\title{
SOCIO-ECONOMIC MODELS TO ASSESS AND POLICY INSTRUMENTS TO STEER THE IMPACT OF NATURE-BASED SOLUTIONS: A REVIEW
}

\author{
RITA MENDONÇA ${ }^{1}$, PETER ROEBELING $^{1,2}$, TERESA FIDÉLIS ${ }^{3} \&$ MIGUEL SARAIVA $^{4}$ \\ ${ }^{1}$ CESAM \& Department of Environment \& Planning, Aveiro University (DAO-UA), Portugal \\ ${ }^{2}$ Wageningen Economic Research, Wageningen University and Research (WUR), The Netherlands \\ ${ }^{3}$ GOVCOPP \& Department of Environment \& Planning, Aveiro University (DAO-UA), Portugal \\ ${ }^{4}$ CEGOT - Centre of Studies in Geography and Spatial Planning, \\ of the Faculty of Arts and Humanities of the University of Porto, Portugal
}

\begin{abstract}
Urban challenges, such as climate change, economic development and land conversion, are increasing and attracting more attention, consequently widening the complexity of urban planning and decisionmaking processes. Nature-based solutions (NBS) are considered to contribute to resolving these emerging urban problems. While models are available to assess the impacts of NBS on urban heat, air quality, flooding and water quality, there are few models that evaluate their socio-economic impacts. Even though statistical models could provide insight in their actual (ex-post) socio-economic impacts, simulation models represent a key tool to urban planning as they provide the opportunity to assess the expected (ex-ante) socio-economic impacts of NBS and, thus, allow better informed decision making before implementation. This paper provides, first, a review of socio-economic models that can assess the impact of NBS (either statistical or simulation) and, second, a review of socio-economic models that assess the effectiveness of policy instruments to steer urban development patterns. Results show that there is a lack of spatially explicit simulation models with the ability to assess the socio-economic impacts of different NBS. Most models that assess socio-economic impacts include statistical (expost), non-spatially explicit or use non-European case studies. Socio-economic impacts evaluated include urban sprawl, housing prices and gentrification. Furthermore, there is a lack of models that have the potential to assess socio-economic impacts of NBS as well as the impact of policy instruments that influence urban development patterns. Hence, it is concluded that there is need for simulation models that allow to assess the expected (ex-ante) socio-economic impacts of NBS as well as the effectiveness of land use policy instruments.
\end{abstract}

Keywords: nature-based solutions, policy instruments, simulation model, socio-economic model.

\section{INTRODUCTION}

Urbanization is taking place at an unprecedented rate, being expected that in 2050 almost $70 \%$ of the world's population will be living in cities. It is likely that half of that urban area is yet to be developed, providing an opportunity for planning and decision-making processes to be developed that increase resilience and create sustainable cities [1], [2]. Hence, urbanization is one of the most urgent challenges as it has serious environmental, social and economic impacts, such as biodiversity loss, air and water pollution, noise, flooding, extreme events, crime, social inequalities, poverty, degraded urban environments and loss of natural spaces in urban and peripheral areas [3]-[5].

Therefore, large parts of the population are exposed to urban environmental conditions that pose threats to their health and well-being. Urbanization processes decreases the available green space for the citizens, increasing environmental injustice, criminality, exclusion of vulnerable groups, raises infrastructure costs and excessive land conversion [6]. This paves the way to support the growing need for the implementation of urban sustainability principles, embedded in social, economic and environmental patterns. The economic dimension entails growth, consumption, productivity and development without 
hindering future demands, while the social dimension encompasses the necessity to meet citizen's needs and promote equality [7].

Unplanned urbanization leads to scattered, low density, discontinuous, leapfrog development, named urban sprawl. This phenomenon is the outcome of individual cumulative decisions involved in land use development, as citizens wish to improve their residential location and property size as well as proximity to urban centres and environmental amenities subject to land availability, income, housing and commuting costs [8]-[10]. Urban sprawl is associated with excessive land and resources consumption, air and water pollution, soil erosion, global warming, loss of natural green space, environmental degradation, biodiversity decline, excessive car use, weakened economies, services provision hampering, health problems, housing shortage, income inequality, segregation and polarization - thus decreasing urban resilience to climate change [11]-[13]. This has become a key environmental and socio-economic challenge and a primary concern for urban planners and policy-makers. In fact, land use change is acknowledged to be one of the main indicators of socio-economic and environmental change [11], [14], [15]. This is a critical and growing issue, creating irreversible impacts in communities worldwide - even where the population is not growing [16], [17]. This leads to segregation and inequality across socio-economic groups, promoting vulnerable citizens to be exposed to environmental hazards and different access to natural amenities and housing conditions, increasing health risks and decreasing life quality [18], [19].

Hence, urbanization is considered the main responsible phenomenon for natural space degradation in cities and is increasing the demand for green spaces [20], [21]. Nature-based solutions (NBS) are a recent concept emerging in European contexts that are considered solutions to increase cities' resilience, defined by the European Commission as "solutions that are inspired and supported by nature, which are cost-effective, simultaneously provide environmental, social and economic benefits and help build resilience" [22], [23]. This concept is related to and integrates other concepts, such as Green and Blue spaces, Ecosystem Services and Ecosystem-Based approaches [24]. NBS provide several environmental, economic and social benefits and co-benefits. Besides the benefits related to air and water quality, flooding control, temperature reduction and biodiversity promotion, they are acknowledged for addressing socio-economic challenges, namely improving the quality of life of vulnerable populations and promoting health, food production, cultural and spiritual benefits, green jobs, recreation and promoting social inclusion [3], [25], [26]. Therefore, NBS can be considered attractive features or amenities that influence citizens' residential location, as households care about the quantity and quality of natural environment surrounding their living spaces to benefit from their ecosystem services. Ergo, having a potential impact on the urban configuration, namely urban sprawl, urban density, housing and land prices [19], [21], [27].

Urban planning and policy are crucial to promote quality of life related to environmental concerns and land use [28]. Nonetheless, policies to steer urbanization processes and promote NBS implementation are yet to be fully integrated in urban planning and decision-making processes [29], [30]. Policy instruments are governance tools that have the potential to steer urbanization and socio-economic patterns [8] and to influence NBS adoption and natural space protection [31], [32]. These can be divided in planning, economic and information instruments. The first include regulations, laws, restrictions, directives, plans and other command and control strategies, imposing behaviours. Economic instruments include taxes, subsidies, trading permits and other payment systems, encouraging behaviours while internalizing externalities. Information instruments entail education, training and other communication and stakeholder engagement actions, such as 
workshops, surveys and certifications [8], [33], [34]. Dorst et al. [35] advocate that a holistic governance direction, including different planning and economic policies, is the way to implement urban sustainability solutions. According to Ferrari et al. [36], integrated planning that consider land and spatial development can contribute to NBS implementation. Berre et al. [37] and Du et al. [38] also underpin the importance of planning, legislation and regulations in curbing urban sprawl. Moreover, Mendonça et al. [8] demonstrated that economic instruments, such as land and property taxes as well as public transport subsidies, have the potential to curb urban sprawl, gentrification and work alongside amenities. Land, property and transport taxes and subsidies have also been considered effective anti-sprawl policies by other authors [10], [14]. Several other authors demonstrate the crucial role that information instruments have in NBS implementation and sustainability promotion [34], [39], [40].

However, there still is limited integrated research on socio-economics, land use patterns and NBS [13], as NBS are considered a recent concept and sprawled urbanization is still a major concern [16], [23]. Policy instruments, despite acknowledged as capable of steering urbanization patterns, are mostly superficially addressed, and their connection with NBS is rather thin [34]. Moreover, NBS literature focusses mostly on environmental benefits, while few studies assess social and economic benefits as well as policies [23]. Hence, there is a need to develop a robust evidence-base and framework regarding NBS socio-economic benefits and their integration in urban policy [3].

Modelling is a relevant tool to build an evidence-base, advise policy makers on the potential impacts of NBS and NBS policies on urbanization, socio-economic and environmental dynamics [8]. Statistical models facilitate ex-post assessments and are based on large amounts of observed data to derive statistical relationships [41]. With simulation models, ex-ante assessments are possible, allowing for long-term predictions of different scenarios without the need for large amounts of observed data [8], [42]. Simulation models are increasingly used to assess urban policy, urbanization and environmental development patterns [43], [44]. Statistical and simulation models can be economic or not, depending on whether they are based on agents that maximize their utility in an optimization perspective, assessing their willingness to pay for goods [42]. Economic models are crucial in modelling environmental amenities, socio-economic behaviour as well as policy and pricing dynamics. In fact, non-economic models struggle to integrate decision making, can only assess socio-economic patterns implicitly and fail to simulate diffused urban forms [28], [45], [46].

Finally, both can be spatially explicit, using a real case study and heterogeneity across space or not. Nonetheless, spatially explicit models allow for a better understanding of future trends and are more realistic, thus with more applicability, namely for socioeconomic dynamics, land use change and policy [8], [47]. Overall, economic spatially explicit simulation models are preferred to model different socio-economic and urbanization patterns as well as NBS under policy instruments scenarios [8], [48].

Nevertheless, these models are still considered scarce in literature, as NBS is a relatively recent concept and most studies are empirical, reviews or conceptual with lack of modelling and mostly related to other topics than socio-economic dynamics. Moreover, there is a shortage of studies that assess NBS environmental, social and economic impacts together [23]. There is also a shortage of studies that have assessed urban sprawl containment with different economic and socio-demographic structures and policies effectiveness [17]. Castro et al. [42] also argues that social patterns are less studied than other aspects and that more than one dimension should be evaluated at the same time. 
On the other hand, there is also a lack of reviews that aim to understand the availability and current trends of models that can assess socio-economic patterns as well as NBS and policy instruments. Castro et al. [42] and Irwin [49] review economic models of land use change, the latter including policy analysis. Walter and Schaper [50] and Michetti and Zampieri [48] analyse economic models with amenities, but neither assesses socioeconomic patterns or policy instruments. Deng and Li [47] and Ren et al. [46] review on spatially explicit simulation models, but without any consideration for economic models or NBS-related concepts nor instruments, while Noszczyk [41] focus on statistical models of land use change. Finally, Huang et al. [51] assess economic simulation models, land use change and socio-economic patterns, but not spatially explicit models neither NBS nor instruments.

Hence, the present study aims to tackle this literature gap by providing, first, a review of socio-economic models that can assess the impact of NBS, considering the dichotomies statistical/simulation, economic/non-economic, spatially explicit/non-spatially explicit and, secondly, which of these models also have the potential to assess the effectiveness of policy instruments to steer urban development patterns. To this end, a literature review and content analysis was performed.

The next section presents the methodology, followed by the results and discussion section that entails the model characteristics (Section 3.1) as well as the content (Section 3.2) and instrument (Section 3.3) analysis and, finally, the conclusion section.

\section{METHODOLOGY}

A snowball literature search was carried-out based on the literature review in Mendonça et al. [8], following [52]. The search includes all papers that cited the previously used papers in this paper up to 2020. As only English written peer-reviewed papers were found, papers were only excluded by content after analysis.

A total of 571 papers was found during the initial search and all abstracts were read. Considering Fig. 1, it is possible to observe that, during that process, 427 papers were excluded for being out of scope, i.e., not using socio-economic models for NBS assessment. In turn, all remaining 144 papers were fully read, leading to an additional exclusion of 12 papers for not meeting the same criteria. Hence, for the present study, 132 papers were analysed - covering the period 2004 to 2020 . The policy instruments were then assessed within the previously selected papers, not representing itself an exclusion criteria. All NBS related concepts were accepted, including green spaces, green infrastructure, amenities, and open space, under the assumption that models that assess these types of concepts can assess NBS as well (considering NBS is an umbrella concept and that NBS is still a recent concept [23], [35]). Socio-economic impacts assessed include urban sprawl and related concepts, such as densification, housing location, urban expansion, segregation, income, quality of life, housing, land price and transport costs. Finally, despite most papers mentioning policy, only papers that assessed policy instruments were considered for the instrument analysis. For space-saving reasons, not all the papers present in the analysis (and results) were included in the discussion of the results.

For the analysis, a data sheet was developed with the author, paper and content information, including type of model (simulation/statistical, economic/non-economic, spatially explicit/non-spatially explicit), type of socio-economic impact, location of the study (European or not), and instrument assessment (planning, economic and information). This information was collected to understand the availability of socio-economic models, current trends and policy instruments integration in the socio-economic and NBS urban planning. 


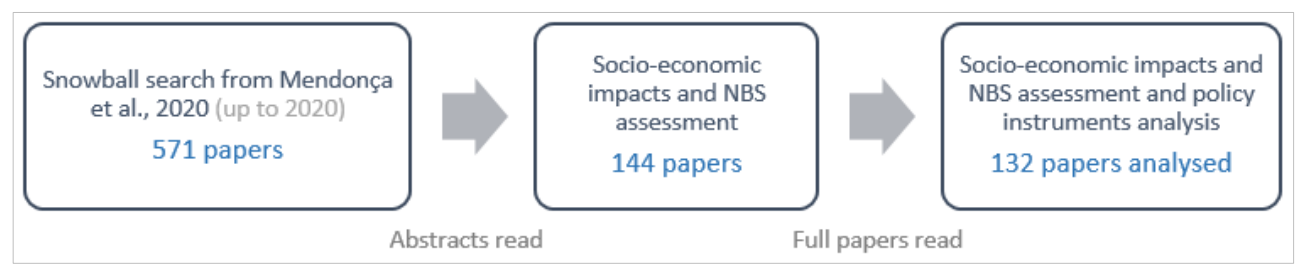

Figure 1: Literature review process.

\section{RESULTS AND DISCUSSION}

This section presents the results analysis and discussion, first assessing the overall model characteristics (Section 3.1), then the content of the papers regarding the socio-economic impact (Section 3.2) and, finally, the instrument analysis (Section 3.3).

\subsection{Model characteristics}

For the model characteristics, Fig. 2 shows the quantitative analysis of the models' features, including if they are statistical/simulation, economic/non-economic and spatially explicit/non-spatially explicit as well as the case study being European or not. Most of the assessed papers are statistical (58\%), economic (70\%) and not spatially explicit (62\%). In addition, most papers do not include a European case study $(76 \%)$.
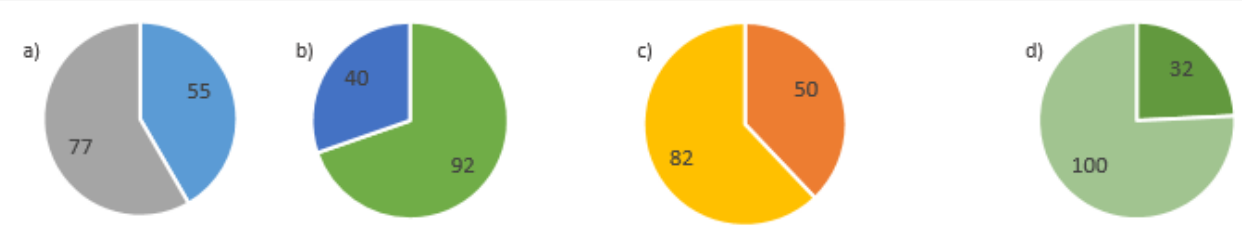

- Simulation $=$ Statistical $=$ Economic $=$ Non-economic $=$ Spatially explicit $=$ Non-spatially explicit $\mid$ European $=$ Non-European

Figure 2: Model characteristics of all papers. (a) Simulation/statistical; (b) Economic/ non-economic; (c) Spatially explicit/non-spatially explicit; and (d) European/ non-European case study.

Fig. 3 presents the model characteristics that are considered more suitable, according to the assessed literature, of socio-economic models to assess NBS and policy instruments, including simulation, economic, spatially explicit as well as models that combine more than one of these characteristics. It is shown that, within the 132 papers analysed, $32 \%$ of the papers are simulation and economic models, $11 \%$ are simulation and spatially explicit models, $17 \%$ are economic and spatially explicit models and, finally, less than $2 \%$ of the papers are simulation, economic and spatially explicit models.

These results show that, even though simulation and spatially explicit models are considered most suitable to assess socio-economic patterns and NBS, these are rarely used in literature [17], [48], [53]. This is in line with Hanson et al. [23] and Wang and Xiang [13] results, which find that simulation and spatially explicit models that assess NBS and 


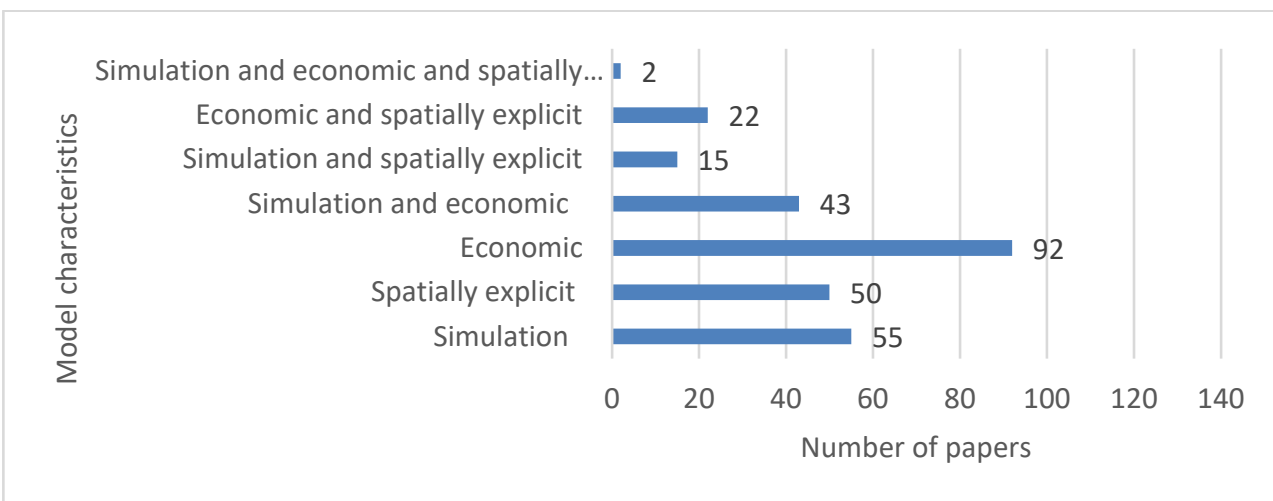

Figure 3: Model characteristics and combinations of the assessed simulation, economic and/or spatially explicit papers.

socio-economic impacts are scarce. Nevertheless, most of the assessed papers used economic approaches, which is expected as socio-economic impacts were a criteria for the papers selection. This highlights the fact that these are the most relevant models for socioeconomic and environmental approaches as they consider the integration of individual behaviour, representing NBS attractiveness and citizens' willingness to pay for them [8], [46]. Despite most models being economic, there is a lack of economic, spatially explicit and simulation models - pinpointing the scarcity of simulation and spatially explicit models. In fact, besides the SULD (Sustainable Urbanizing Landscape Development) model used by [8], [54], [55], only other model was found in two papers that was simulation, economic and spatially explicit [45], [56], constituting a literature gap that was highlighted by other authors and evidencing the need to develop models able to predict urbanization patterns, focusing on NBS socio-economic connections with spatial distribution and optimization [48], [57].

Other significant trends found in literature consist in most papers not having a European case study. This is noteworthy because urbanization is considered specific in Europe, where high income households live in city centres and not in peripheral areas (which is the case in America) - an aspect that needs to be taken into consideration when steering NBS adoption and socio-economic trends [58]. Moreover, this study did not use NBS as the sole selection criteria, including other related concepts that represented the vast majority. This might explain why the selection has more non-European case studies than if only the NBS concept was considered, as NBS is a key concept in Europe. This also highlights the novelty of the concept, showing that it is not yet that well embedded in urbanization and socio-economic modelling literature [23].

\subsection{Content analysis}

For the content analysis, Table 1 presents an overview of the socio-economic impacts found in the assessed papers. Note that in one paper more than one socio-economic impact can be modelled. The impacts were grouped by proximity of concepts, as different terminologies were used in different studies. It is possible to see that the impacts related to urbanization, such as urban sprawl, housing location choices and urban density, were the most evaluated, 
Table 1: Socio-economic impact assessed in the reviewed papers.

\begin{tabular}{|l|c|}
\hline Socio-economic impact & Number of papers \\
\hline Urban sprawl/housing location/density & 87 \\
\hline Housing, land or transport prices & 49 \\
\hline Segregation/income & 19 \\
\hline Life quality & 9 \\
\hline
\end{tabular}

followed by price related impacts (housing, land and transport), segregation and income impacts and, finally, the least assessed impact is related to citizens' life quality.

The most simulated impact was urban sprawl and related concepts, such as housing location choices, density and compactness. This trend could be expected as this impact is directly related to land use and conversion modelling - a field that is well developed [46]. Moreover, it is widely acknowledged that NBS and overall amenities have a key role in urban form, as households make residential choices regarding the location of these attractive places [16], [57]. In fact, amenities are recognized to be able to influence urban sprawl, depending on their location, size and attractiveness [8], [59]. In addition, the lack of amenities leads to a more sprawled urban area [9]. Only one study did not find a significant relation between amenities and land conversion, despite being a statistical study based in China [60].

The second most assessed impact is related to housing, land and transport prices. Accruing from the NBS attractiveness and housing location choices, households are willing to pay more to be near these places - consequently increasing the land and property prices as widely mentioned in literature [32], [61]. Transport costs are also acknowledged to have an impact on household decisions and, thus, on urban form - influencing their willingness to pay to be near attractive places and changing their commuting costs [62].

The least mentioned impacts include segregation, income and quality of life. This is in line with Hanson et al. [23] findings, stating that the least addressed subjects are related to social justice and equality. NBS are acknowledged to have a significant impact in these subjects, as half of the NBS's value is related to recreational purposes [63]. Overall, NBS can increase quality of life and welfare, depending on the population characteristics, such as income [16]. In fact, low-income households usually have less access to highly attractive places, leading to segregation, which might be promoted or attenuated by NBS implementation [4], [18].

\subsection{Instrument analysis}

The second part of the review included the study of the presence of policy instruments (planning, economic or information) in the assessed papers. Within the 132 papers evaluated, 37 (28\%) modelled the impact of policy instruments on socio-economic and NBS dynamics. Fig. 4 presents the type of model used in these papers, including the considered desired characteristics as well as combinations. Results show that most papers that evaluate policy instruments are simulation $(68 \%)$ or economic $(84 \%)$, while only few are spatially explicit (16\%). The majority are simulation and economic models $(60 \%)$ but not economic and spatially explicit $(8 \%)$ or simulation, economic and spatially explicit models $(0 \%)$. 


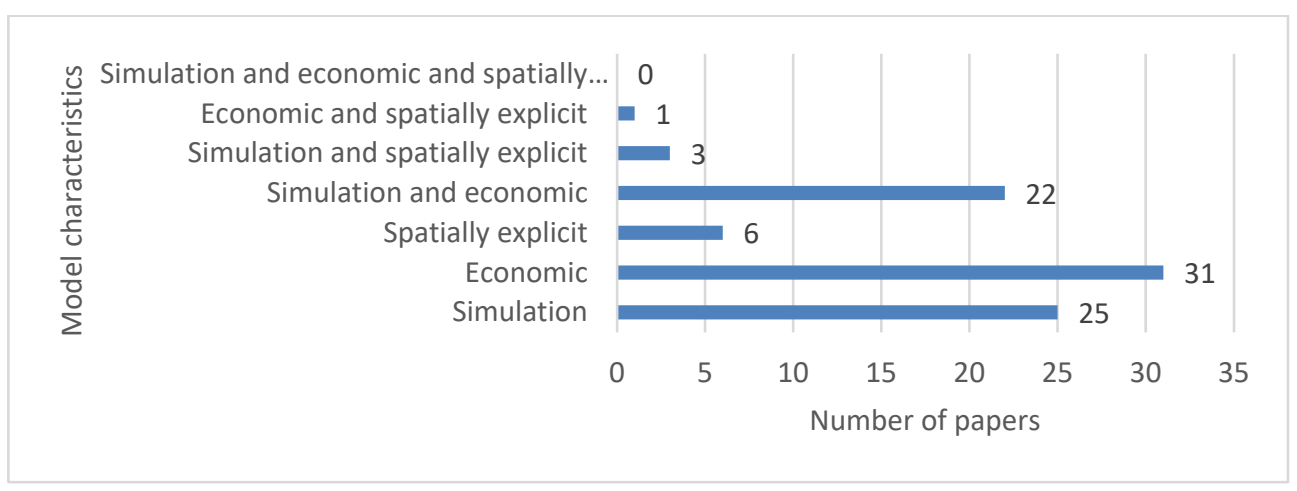

Figure 4: Model characteristics of the papers that include policy instrument analysis.

Regarding the type of policy instrument, Table 2 shows the instrument types modelled in the 37 papers. Results show that economic instruments were the most assessed (54\%), followed by planning (32\%) and planning and economic instruments (14\%); no information instruments were found.

Table 2: Instrument type assessed in the reviewed papers.

\begin{tabular}{|l|c|}
\hline Instrument type & Number of papers \\
\hline Planning & 12 \\
\hline Economic & 20 \\
\hline Information & 0 \\
\hline Planning and economic & 5 \\
\hline
\end{tabular}

Most of the analysed models did not model policy instruments, which is in line with Sarabi et al. [34] and Hanson et al. [23] findings, that most policy instrument related literature is superficial and theoretical. However, contrary to the overall models results, most models that assess policy instruments as well as socio-economic patterns and NBS are simulation and economic models. Indeed, it is acknowledged in literature that simulation models are the desired approach to assess their effectiveness and predict different scenario outcomes [43], [44]. Most models are also economic, which is expected due to the socioeconomic criteria and because most instruments found were economic. However, most papers do not adopt a spatially explicit approach, which decreases the applicability and understanding of future trends and patterns [8], [47]. Moreover, combinations of simulation and spatially explicit as well as economic and spatially explicit are almost non-existent, and no paper was found that combine a simulation, economic and spatially explicit approach. In this sense, the SULD model continues to be the only model found with these characteristics that can model socio-economic patterns, NBS while assessing policy instruments [8], [54], [55].

Regarding the instrument types assessed, the most modelled in literature are economic. This is as expected given urbanization is often considered a market failure related to the under-pricing of natural resources [13]. Most mentioned economic instruments include property, land and transport taxes as well as transport subsidies. Property prices were found 
to be effective anti-sprawl policies, influencing the city form and living space [8], [14], [64]. Conversely, the effectiveness of land taxes is not straightforward - some authors found it effective in curbing sprawl [64]-[66] while others found it ineffective or even promoting sprawl and segregation [53], [67]. Its effectiveness might be case specific, depending on population characteristics and land prices [8], [53]. Transport pricing is also acknowledged to have an influence on urban design [62], [68]. However, its urbanizationsteering potential depends on the complex relation between car and public transport use. Overall, transport taxes might lead to sprawl while public transport subsidies might encourage compactness [8], [10].

Regarding planning instruments, it includes urban growth boundaries, zoning and land acquisition to control development. Despite considered as effective anti-sprawl policies by some non-European authors [69], [70], others consider that they might work but impose high costs on households by reducing housing supply and increasing land prices [71] or even that they hardly can control major expansions [72]. In fact, authors that model both economic and planning instruments found, in general, that a combination might be adequate [73], but economic instruments are considered more effective in controlling urbanization by encouraging behaviour (rather than imposing them) and increasing citizens' quality of life [53], [74]. No information instruments were found in the literature, which is most likely related to the fact that these are related to citizen's engagement and awareness promotion, hence difficult to model despite being considered essential in urbanization dynamics [33], [34], [40].

\section{CONCLUSION}

Overall, there is a need for more research on socio-economic urban development patterns and NBS as well as to promote effective policies to steer these. This study has the objective to perform a literature review on socio-economic models that assess NBS and potential policy instruments. The study includes a snowball research on Mendonça et al. [8], as to grasp the literature developments and gaps. Even though most assessed models are economic, they are also mostly statistical, non-spatially explicit and use non-European case studies, while only one simulation economic spatially explicit model was found. However, this model did not assess policy instruments in a spatially explicit way. In fact, policy instruments were only found in $28 \%$ of the analysed studies, mostly economic and simulation (68\%) but not spatially explicit. No simulation economic and spatially explicit models were found that assessed socio-economic impacts, NBS and policy instruments. Hence, the SULD model, used in Mendonça et al. [8] is considered the most suitable option to simulate socio-economic patterns, NBS adoption and policy instruments effectiveness in a spatially explicit perspective. Most papers use non-European case studies, most likely because NBS-related concepts represent the majority used, allowing to conclude that NBS (widely used in Europe) are yet to be fully integrated in this field. For the content analysis, most assessed socio-economic impacts include urban sprawl, housing, land and transport prices followed by segregation and income, in which NBS are acknowledged to have an impact. Regarding policy instruments, economic instruments were the most modelled, followed by planning and combined economic and planning. In fact, no information instruments were found and economic instruments are considered most effective in steering socio-economic patterns.

Hence, there is a need for more studies regarding the integration of NBS and policy instruments in socio-economic planning trends, namely of social impacts in European case studies. There is also a shortage of simulation, economic and especially spatially explicit socio-economic models that can integrate NBS and policy instruments. 
In conclusion, current urbanization patterns pave the way for an increasing necessity of a more socio-economic-driven urban planning - integrating NBS and policy instruments to attain sustainable development goals. Economic spatially explicit simulation modelling might have a crucial role by allowing an ex-ante prediction of different scenario outcomes.

\section{ACKNOWLEDGEMENTS}

This work was supported by the UNaLab project (Grant Agreement No. 730,052, Topic: SCC-2-2016-2017: Smart Cities and Communities Nature-based solutions). Thanks also for the financial support to the PhD grants of R. Mendonça (SFRH/BD/147005/2019). Finally, thanks are due to FCT/MCTES for the financial support to (UIDP/50017/2020+ UIDB/50017/2020), through national funds.

\section{REFERENCES}

[1] Brown, Z., Oueslati, W. \& Jérôme, S., Links between urban structure and life satisfaction in a cross-section of OECD metro areas. Ecological Economics, 129, pp. 112-121, 2016.

[2] Childers, D., Bois, P., Hartnett, H., McPhearson, T., Metson, G. \& Sanchez, A., Urban ecological infrastructure: An inclusive concept for the non-built urban environment. Elementa: Science of the Anthropocene, 7, p. 46, 2019.

[3] Lafortezza, R. \& Sanesi G., Nature-based solutions: Settling the issue of sustainable urbanization. Environmental Research, 172, pp. 394-398, 2019.

[4] Ruiz-Luna, A., Bautista, R., Hernández-Guzmán, R. \& Camacho-Valdez, V., Uneven distribution of urban green spaces in a coastal city in northwest Mexico. Local Environment, 24(5), pp. 458-472, 2019.

[5] Mondal, B. \& Das, N., How residential compactness and attractiveness can be shaped by environmental amenities in an industrial city? Sustainable Cities and Society, 41, pp. 363-377, 2018.

[6] Säumel, I., Reddy, S.E. \& Wachtel, T., Edible city solutions-one step further to foster social resilience through enhanced socio-cultural ecosystem services in cities. Sustainability, 11, 972, 2019.

[7] Du, Q., Wu, C., Ye, X., Ren, F. \& Lin, T., Evaluating the effects of landscape on housing prices in urban China. Economische en Sociale Geografie, 109(4), pp. 525$541,2018$.

[8] Mendonça, R. et al., Assessing economic instruments to steer urban residential sprawl, using a hedonic pricing simulation modelling approach. Land Use Policy, 92, 104458, 2020.

[9] Carrión-Flores, C. \& Irwin, E.G., Determinants of residential land use conversion and sprawl at the rural-urban fringe. American Journal of Agricultural Economics, 86(4), pp. 889-904, 2004.

[10] Cai, Q., Wang, Z. \& Xiao, L., The effect of transportation and housing subsidies on urban sprawl. Journal of Systems Science and Information, 6(3), pp. 237-248, 2018.

[11] Gómez-Antonio, M., Hortas-Rico, M. \& Li L., The causes of urban sprawl in Spanish urban areas: A spatial approach. Spatial Economic Analysis, 11(2), pp. 219247, 2016.

[12] Mohammady, M. \& Delavar, M.R., Urban sprawl assessment and modeling using landsat images and GIS model. Earth Systems and Environment, 2, p. 155, 2016.

[13] Wang, Y. \& Xiang, P., Urban sprawl sustainability of mountainous cities in the context of climate change adaptability using a coordination model. Sustainability, $\mathbf{2}$, p. 11, 2019. 
[14] Ermini, B. \& Santolini, R., Urban sprawl and property tax of a city's core and suburbs: evidence from Italy. Regional Studies, 51(9), pp. 1374-1386, 2017.

[15] Marraccini, E. et al., Common features and different trajectories of land cover changes in six western Mediterranean urban regions. Applied Geography, 62, pp. 347-356, 2015.

[16] Lima, F., Thompson, C., Aspinall, P. \& Bell, S., Communities facing urban depopulation: Exploring people's environmental preferences. A case study of Lisbon, Portugal. Cities \& Health, 2020.

[17] Salvati, L. \& Lamonica, G.R., Containing urban expansion: Densification vs greenfield development, sociodemographic transformations and the economic crisis in a southern European city, 2006-2015. Ecological Indicators, 110, 105923, 2020.

[18] Schaeffer, Y. \& Tivadar, M., Measuring environmental inequalities: Insights from the residential segregation literature. Ecological Economics, 164, 106329, 2019.

[19] Schaeffer, Y., Cremer-Schulte, D., Tartiu, C. \& Tivadar, M., Natural amenity-driven segregation: Evidence from location choices in French metropolitan areas. Ecological Economics, 130, pp. 37-52, 2016.

[20] Régnier, C., Open space preservation in an urbanization context. Journal of Regional Science, 60, pp. 443-458, 2020.

[21] Salvati, L., Gitas, I., Valeria, T., Giacomo, D., Saradakou, E. \& Carlucci, M., Sprawl matters: The evolution of fringe land, natural amenities and disposable income in a Mediterranean urban area. Environment, Development and Sustainability, 19, pp. 727-743, 2017.

[22] European Commission (EC). Nature-based solutions. https://ec.europa.eu/info/ research-and-innovation/re-654search-area/environment/nature-basedsolutions_en.

Accessed: 10 Mar. 2021.

[23] Hanson, H., Wickenberg, B. \& Olsson, J., Working on the boundaries-How do science use and interpret the nature-based solutions concept? Land Use Policy, 90, $104302,2020$.

[24] Escobedo, J., Giannico, V., Jim, Y., Sanesi G. \& Lafortezza R., Urban forests, ecosystem services, green infrastructure and nature-based solutions: Nexus or evolving metaphors? Urban Forestry and Urban Greening, 37, pp. 3-12, 2018.

[25] Watkin, L., Ruangpan, L., Vojinovic, Z., Weesakul, S. \& Torres, A., A framework for assessing benefits of implemented nature-based solutions. Sustainability, 11, p. 6788, 2017.

[26] De Valck, J., Beames, A., Liekens, I., Bettens, M., Seuntjens, P. \& Broekx, S., Valuing urban ecosystem services in sustainable brownfield redevelopment. Ecosystem Services, 35, 139-149, 2019.

[27] Frantzeskaki, N., Seven lessons for planning nature-based solutions in cities. Environmental Science and Policy, 93, pp. 101-111, 2019.

[28] Kaviari, F., Mesgari, M., Seidi, E. \& Motieyan, H., Simulation of urban growth using agent-based modeling and game theory with different temporal resolutions. Cities, 95, 102387, 2019.

[29] Davis, M., Abhold, K., Mederake, L. \& Knoblauch, D., Nature-based solutions in European and national policy frameworks, Deliverable 1.5 Naturvation, Grant 730243, European C, 50 pp., 2013.

[30] Milan, B., Kapfer, D. \& Creutzig, F., A systematic framework of location value taxes reveals dismal policy design in most European countries. Land Use Policy, 51, pp. 335-349, 2016. 
[31] Hawxwell, T. et al., Municipal governance recommendations for front-runner cities. UNaLab D5.2 Deliverable, 126 pp., 2019.

[32] Farja, Y., Price and distributional effects of privately provided open space in urban areas. Landscape Research, 42(5), pp. 543-557, 2017.

[33] Artmann, M. \& Sartison, K., The role of urban agriculture as a nature-based solution: A review for developing a systemic assessment framework. Sustainability, 10, p. 1937, 2018.

[34] Sarabi, S., Han, Q., Romme, A., Vries, B. \& Wendling, L., Key enablers of and barriers to the uptake and implementation of nature-based solutions in urban settings: A review. Resources, 8, p. 21, 2019.

[35] Dorst, D., van der Jagr, A. \& Runhaar, H., Urban greening through nature-based solutions-key characteristics of an emerging concept. Sustainable Cities and Society, 49, 101620, 2019.

[36] Ferrari, B., Quatrini, V., Barbati, A., Corona, P., Masini, E. \& Russo, D., Conservation and enhancement of the green infrastructure as a nature-based solution for Rome's sustainable development. Urban Ecosystems, 22, pp. 865-878, 2019.

[37] Berre, I., Maulpoix, A., Thériault, M. \& Gourmelon, F., A probabilistic model of residential urban development along the French Atlantic coast between 1968-2008. Land Use Policy, 50, pp. 461-478, 2016.

[38] Du, M., Zhang, X., Wang, Y. \& Li, H., An operationalizing model for measuring urban resilience on land expansion. Habitat International, 102, 102206, 2020.

[39] Ingold, K., Stadelmann-Steffen, I. \& Kammermann, L., The acceptance of instruments in instrument mix situations: Citizens' perspective on Swiss energy transition. Research Policy, 48(10), 2019.

[40] Ríos-White, M., Roebeling, P., Valente, S. \& Vaittinen, I., Mapping the life cycle cocreation process of nature-Based solutions for urban climate change adaptation. Resources, 9(4), p. 39, 2020.

[41] Noszczyk, T., A review of approaches to land use changes modelling. Human and Ecological Risk Assessment: An International Journal, 25, pp. 1377-1405, 2019.

[42] Castro, L., Härtl, F., Ochoa, S., Calvas, B., Izquierdo, L. \& Knoke, T., Integrated bioeconomic models as tools to support land-use decision making: A review of potential and limitations. Journal of Bioeconomics, 20, pp. 183-211, 2018.

[43] Goundaridis, D., Chorianopoulos, I. \& Koukoulas, S., Exploring prospective urban growth trends under different economic outlooks and land-use planning scenarios: The case of Athens. Applied Geography, 90, pp. 134-144, 2018.

[44] Li, S., Horváth, L., Pedde, S., Pintér, L., Rounsevell, M. \& Harrison, P., Integrated modelling of urban spatial development under uncertain climate futures: A case study in Hungary. Environmental Modelling \& Software, 96, pp. 251-264, 2017.

[45] Filatova, T., Empirical agent-based land market: Integrating adaptive economic behaviour in urban land-use models. Computers, Environment and Urban Systems, 54, pp. 397-413, 2015.

[46] Ren, Y., Lu, Y., Comber, A., Fu, B., Harris, P. \& Wu, L., Spatially explicit simulation of land use/land cover changes: Current coverage and future prospects. Earth Science Reviews, 190, pp. 398-415, 2019.

[47] Deng, X. \& Li, Z., A review a review on historical trajectories and spatially explicit scenarios of land-use and land-cover changes in China. Journal of Land Use Science, 11, pp. 709-724, 2016.

[48] Michetti, M. \& Zampieri, M., Climate-Human-Land interactions: A review of major modelling approaches. Land, 3, pp. 793-811, 2014. 
[49] Irwin, E., New directions for urban economic models of land use change: Incorporating spatial dynamics and heterogeneity. Journal of Regional Science, 50, pp. 65-91, 2010.

[50] Waltert, F. \& Schläpfer, F., Landscape amenities and local development: A review of migration, regional economic and hedonic pricing studies. Ecological Economics, 70, pp. 141-152, 2010.

[51] Huang, Q., Parker, D., Filatova, T. \& Sun, S., A review of urban residential choice models using agent-based modelling. Environment and Planning B: Planning and Design, 40, 2013.

[52] Shahrohki, H. \& Bachmann, C., Designing computable general equilibrium models for transportation applications. Transport Reviews, 38, pp. 737-764, 2018.

[53] Filatova, T., Voinov, A. \& Veen, A., Land market mechanisms for preservation of space for coastal ecosystems: an agent-based analysis. Environmental Modelling \& Software, 26, pp. 179-190, 2011.

[54] Roebeling, P. et al., Assessing the socio-economic impacts of green/blue space, urban residential and road infrastructure projects in the confluence (Lyon): A hedonic pricing simulation approach. Journal of Environmental Planning and Management, 60, pp. 482-499, 2017.

[55] Saraiva, M., Roebeling, P., Sousa, S., Teotónio, C., Palla, A. \& Gnecco, I., Dimension of shrinkage: Evaluating the socio-economic consequences of population decline in two medium-sized cities in Europe, using the SULD decision support tool. Environment and Planning B: Planning and Design, 44, pp. 1122-1144, 2017.

[56] Filatova, T., Veen, A. \& Parker, D., Land market interactions between heterogeneous agents in a heterogeneous landscape-tracing the macro-sale effects of individual trade-offs between environmental amenities and disamenities. Journal of Agricultural Economics, 57, pp. 431-457, 2009.

[57] Colléony, A. \& Shwartz, A., Beyond assuming co-benefits in nature-based solutions: A human-centered approach to optimize social and ecological outcomes for advancing sustainable urban planning. Sustainability, 11, p. 4924, 2019.

[58] Lemoy, R., Raux, C. \& Jensen, P., An agent-based model of residential patterns and social structure in urban areas, systèmes, modélisation. Géostatistiques, 512, 2010.

[59] Unal, M. \& Uslu, C., Evaluating and optimizing urban green spaces for compact urban areas: Cukurova district in Adana, Turkey. Journal of Geo-Information, 7(2), p. 70, 2018.

[60] Deng, Y. \& Srinivasan, S., Urban land use change and regional access: A case study in Beijing. China. Habitat International, 51, pp. 103-113, 2016.

[61] Fernandez, M. \& Bucaram, S., The changing face of environmental amenities: Heterogeneity across housing submarkets and time. Land Use Policy, 83, pp. 449460, 2019.

[62] Legras, S. \& Cavailhès, J., Environmental performance of the urban form. Regional Science and Urban Economics, 59, pp. 1-11, 2016.

[63] De Valck, J., Beames, A., Liekens, I., Bettens, M., Seuntjens, P. \& Broekx, S., Valuing urban ecosystem services in sustainable brownfield redevelopment. Ecosystem Services, 35, 139-149, 2019.

[64] Wu, J., Xu, W. \& Alig, R., How do the location, size and budget of open space conservation affect land values? Journal of Real Estate Finance and Economics, 52, pp. 73-97, 2016.

[65] Ayazli, I., An empirical study investigating the relationship between land prices and urban geometry. International Journal of Geo-Information, 8, p. 457, 2019. 
[66] Chen, Y., Li, Z., Lam, W. \& Choi, K., Tradable location tax credit scheme for balancing traffic congestion and environmental externalities. Journal of Sustainable Transportation, 10, pp. 917-934, 2016.

[67] Chen, Y., Effects of development tax on leapfrog sprawl in a thinly traded land market. Land Use Policy, 92, 104420, 2020.

[68] Creutzig, F., How fuel prices determine public transport infrastructure, modal shares and urban form. Urban Climate, 10, pp. 63-76, 2014.

[69] Cho, S., Kim, S., Roberts, R., Lambert, D. \& Kim, T., Effects of land-related policies on land development during a real estate boom and a recession. Growth and Change, 46, pp. 218-232, 2015.

[70] Ma, Q., Integrating ecological correlation into cellular automata for urban growth simulation: A case study of Hangzhou, China. Urban Forestry \& Urban Greening, 51, 126697, 2020.

[71] Sims, K. \& Schuetz, J., Local regulation and land-use change: The effects of wetlands bylaws in Massachusetts. Regional Science and Urban Economics, 39, pp. 409-421, 2009.

[72] Zambon, I., Serra, P., Bencardino, M., Carlucci, M. \& Salvati, L., Prefiguring a future city: Urban growth, spatial planning and the economic local context in Catalonia. European Planning Studies, 25, pp. 1797-1817, 2017.

[73] Ana, A. \& Pines, D., Anti-sprawl policies in a system of congested cities. Regional Science and Urban Economics, 38, pp. 408-423, 2008.

[74] Ardeshiri, A., Ardeshiri, M., Radfar, M. \& Shormasty, O., The values and benefits of environmental elements on housing rents. Habitat International, 55, pp. 67-78, 2016. 